\title{
USAHA KECIL MENENGAH DI BANDUNG MENDUKUNG SUSTAINABLE DESIGN MELALUI PEMBUATAN FURNITUR BERBAHAN LIMBAH KAYU MENGGUNAKAN KONSEP NIRMANA DWIMATRA
}

\author{
Teuku Zulkarnain Muttaqien ${ }^{*}$, Hardy Adiluhung2*
}

\author{
Program Studi S1 Industrial Design Fakultas Industri Kreatif \\ Universitas Telkom \\ Jl. Telekomunikasi, No. 1, Terusan Buahbatu-Bojongsoang, Kec. Dayeuhkolot, Kota Bandung, Kode Pos 40257 \\ Jawa Barat. Indonesia \\ Email: tzulkarnainm@telkomuniversity.ac.id, hardydil@telkomuniversity.ac.id
}

\begin{abstract}
Abstrak
Usaha Kecil Menengah (UKM) memiliki peran penting dalam perekonomian di Indonesia. Usaha furnitur adalah salah satu bentuk UKM yang termasuk kedalam Industri kecil kerajinan, menurut statistik yang dilansir data Bandung, jumlahnya pada tahun 2017 adalah 711 pelaku usaha. Dalam praktiknya industri ini menghasilkan limbah kayu yang jumlahnya besar dan sedikit yang mengolahnya kembali menjadi sesuatu yang bernilai tambah. Penelitian ini bertujuan untuk menghasilkan produk kerajinan berkelanjutan yang menggunakan limbah kayu sebagai bahan dasar untuk menopang kelanjutan usaha ditengah masa pandemi. Artikel ini adalah salah satu hasil penelitian terapan dengan fokus usaha kecil menengah yang mendukung program sustainable design dengan pendekatan pembuatan produk daur ulang. Penelitian ini menggunakan metode nirmana dwimatra dengan pendekatan Participation Action Research (PAR). Hasil dari penelitian ini adalah prototipe kerajinan berbahan baku limbah kayu dari sisa produksi UKM furnitur.
\end{abstract}

Kata Kunci: daur ulang, dwimatra, kerajinan, limbah.

\begin{abstract}
Small and Medium Enterprises (SMEs) have a role in the economy in Indonesia. The furniture business is a form of SME which included in the small handicraft industry, according to statistics reported by Bandung data, the number in 2017 was 711 company. This industry produces large amounts of wood waste only a few reprocesses it into something of added value. This study aims to make sustainable handicraft products that use wood waste as a material to support business continuity amid the pandemic. This article is one of the results of applied research with a focus on small and medium enterprises that espouse sustainable design programs with an approach to making recycled products. This study uses the dwimatra nirmana method with the Participation Action Research (PAR) approach. The result of this research is a craft prototype made from wood waste from the residual production of furniture.
\end{abstract}

Keywords: craft, dwimatra, recycle, waste.

\section{PENDAHULUAN}

Limbah sisa UKM (Usaha Kecil Menengah) furnitur jumlahnya tidak sebanyak limbah yang dihasilkan dari kegiatan rumah tangga, namun limbah ini termasuk salah satu yang sering digunakan oleh pelaku industri kreatif, selain membuat produk meubeler, aktivitas pelatihan mengolah limbah pun kerap dilakukan (Hanum, 2018). Pengolahan limbah menjadi sesuatu yang bernilai lebih dan layak jual saat ini menjadi salah satu solusi yang dapat diambil untuk bertahan disaat pesanan tertunda akibat masa pandemik, tidak hanya UKM furnitur, hampir sebagian besar UKM terkena imbasnya.
Metode ini mendapat perhatian dari berbagai kalangan, para pegiat daur ulang ini ada yang bersifat individu dan komunitas seperti komunitas Kresek di Solo yang bergerak mengumpulkan sampah untuk didaur ulang (Pambudi, 2020), bahkan para pemuda di Lombok membuat acara Daur fest pada tahun 2018 untuk memamerkan produk hasil daur ulang (Rakhman, 2018). Kreativitas membuat benda-benda kebutuhan sehari-hari muncul dari keresahan mereka terhadap sampah yang jumlahnya semakin banyak, bahan limbah yang digunakan beragam, mulai dari plastik, kertas, kaleng sampai dengan kain, namun dalam penelitian ini hanya fokus pada limbah sisa berupa potongan dan serbuk kayu olahan pabrik dan material 


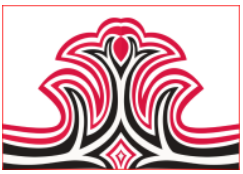

lain yang biasa digunakan di UKM furnitur seperti HPL (High Pressure Laminated), potongan besi dan kaca.

Potensi pasar untuk produk hasil limbah kayu ini cukup besar, terlihat dari respon yang diberikan pada produk limbah dari Indonesia di pameran furnitur IMM International Furnishing Expo di Cologne, Jerman, produk yang dipamerkan mendapat dukungan dari sebuah lembaga bernama Lembaga Ekolabel Indonesia. Keunggulan dari produk tersebut adalah keunikan serta bahan yang digunakan (Rakyat, 2016), selain itu ada produk limbah kayu hasil dari program pengabdian masyarakat yang dilakukan oleh tim dosen dari ISI Surakarta yang ikut dipamerkan di Milan Italia (Perdana, 2018).

Penelitian ini akan mengkaji kemungkinan penerapan unsur-unsur senirupa sebagai nilai tambah pada produk berbasis limbah, unsur yang digunakan disini diambil dari konsep dwimatra, pada prinsipnya, nirmana dwimatra adalah panjang dan lebar pada sebuah bidang datar, tidak memiliki kedalaman atau ketebalan, didalamnya dapat dimasukkan sebuah komposisi titik, garis, bidang, dan bentuk yang disusun sedemikian rupa sehingga didapat kesan ruang, volume, ilusi dan tipuan optik (Dyanrch, 2015). Dalam sebuah benda berbentuk tiga dimensi tentunya terdapat bidang datar, memiliki panjang tinggi dan lebar, sebagai contoh; sebuah meja memiliki daun meja yang permukaannya datar, sebuah lemari memiliki dinding dan daun pintu.

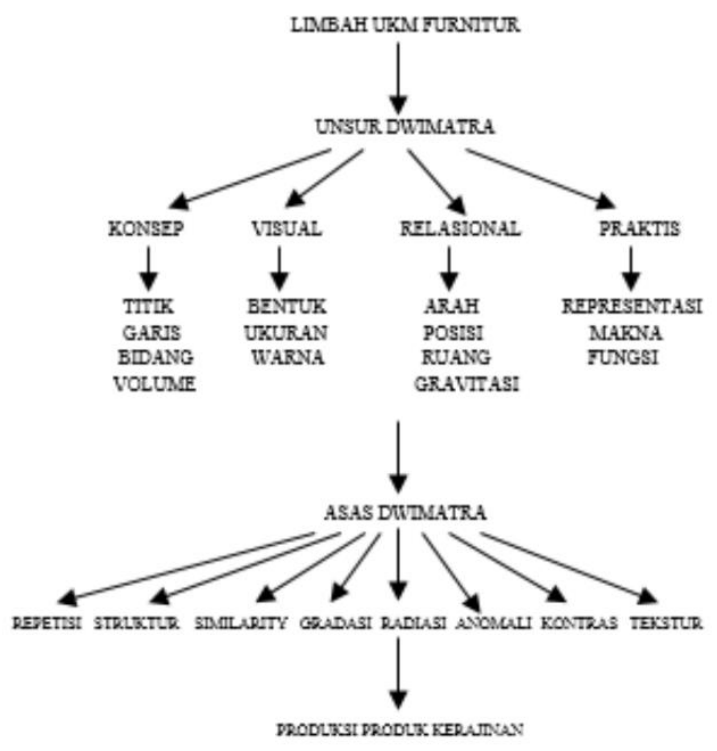

Gambar 1. Alur Proses Pembuatan Produk Limbah UKM Furnitur (Muttaqien, 2020)
Gorga : Jurnal Seni Rupa

Volume 10 Nomor 01 Januari-Juni 2021

p-ISSN: 2301-5942 | e-ISSN: 2580-2380

\section{KAJIAN TEORI}

\section{Teori Nirmana Dwimatra}

Nirmana adalah tata unsur-unsur rupa seperti titik, garis, bidang, bentuk, warna dan tekstur menjadi satu kesatuan yang tampak indah, walaupun arti dari nirmana sendiri adalah kosong tanpa makna, namun hasil akhir dari karyanya diharapkan dapat memberi dampak nilai estetis. Unsur-unsur nirmana dibagi menjadi empat, yaitu: 1). Unsur konseptual, dimana unsur ini tidak terlihat secara kasat mata namun ada, membentuk unsur visual secara maya. Unsur-unsur ini terdiri dari titik, garis, bidang, dan volume, 2). Unsur visual, dimana unsur konseptual tampak menjadi nyata, hadir dalam bentuk visual melalui bantuan alat-alat gambar. Unsur-unsur visual terdiri dari bentuk, ukuran, dan warna, 3). Unsur relasional, unsur ini mengatur penempatan dan hubungan antar bentuk menjadi sebuah komposisi yang dapat menimbulkan kesan tertentu. Unsur-unsur relasional terdiri dari arah, posisi, ruang, dan gravitasi, dan 4). Unsur praktis, unsur ini menjadi dasar dari fungsi lanjutan dari karya nirmana. Unsur praktis terdiri dari representasi, makna, dan fungsi (Thabroni, 2018).

\section{Asas Dwimatra}

Asas dalam dwimatra pada prinsipnya tidak memiliki acuan atau patokan yang absolut, masing-masing ahli memiliki persepsinya sendiri, asas nirmana adalah sebagai berikut: 1). Keseimbangan, keseimbangan yang dimaksud disini adalah keseimbangan visual, kesan seimbang menimbulkan kesan nyaman dilihat. Ada beberapa keseimbangan diantaranya adalah; keseimbangan simetris, tersembunyi, memancar, dan sederajat, 2). Kesatuan / Selaras / Harmoni, prinsip kesatuan disini adalah adanya saling hubungan antar unsur yang disusun, 3). Penekanan / Emphasis / Center of Interest, karya yang memiliki area fokus utama lebih mudah menarik perhatian daripada karya yang datar, 4). Irama / Ritme / Rhythm, irama yang dihasilkan dalam sebuah karya seni rupa dihasilkan dari pengulangan motif yang sama dengan menerapkan aturan transformasi tertentu, 5). Proporsi, perlu perbandingan yang seimbang dalam membuat sebuah karya agar tidak terlihat aneh, tetapi dalam konteks tertentu ketidak seimbangan yang diatur sedemikian rupa secara sengaja dapat memberi kesan positif, 6). Kontras, harmoni yang ditimbulkan dari tumpang tindihnya unsur-unsur yang berlawanan, terang $><$ gelap, kasar $><$ halus, ketidakselarasan ini digunakan untuk membangun gaya ironi atau penekanan terhadap sesuatu, 7). Kesederhanaan, tidak selalu yang rumit itu baik, semakin sederhana sebuah karya dan mencapai tujuan maka karya tersebut semakin efektif karya 


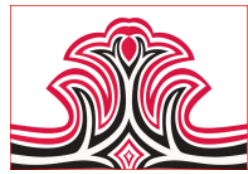

tersebut, dan 8). Kejelasan / Clarity / Discoverability, prinsip ini artinya mudah dipahami, karena karya dibuat untuk dimengerti oleh orang lain (Thabroni, 2018).

\section{METODE PENELITIAN}

Metode yang digunakan dalam penelitian ini menggunakan metode penelitian deskriptif kualitatif, metode ini mendeskripsikan kejadian dilapangan sesuai dengan kenyataan, proses pembuatan konsep produk daur ulang hingga produknya jadi melibatkan dua bidang keilmuan, bidang seni rupa dan desain dengan pendekatan konsep dwimatra dan praktisi kerja kayu.

Proses selanjutnya adalah dengan membuat konsep produk furnitur sederhana yang biasa dikerjakan oleh praktisi kerja kayu dengan pendekatan prinsip dasar seni rupa, praktisi kerja kayu sudah terbiasa membuat produk furnitur namun perlu arahan dalam menerapkan prinsip dwimatra, pembuat konsep terbiasa membuat konsep dwimatra tetapi belum terbiasa dengan media yang berasal dari sisa produksi. Unsur-unsur yang akan diterapkan diantaranya adalah:

\section{Garis}

Garis adalah himmpunan dari titik yang jumlahnya lebih gari satu titik, berbeda dengan titik, garis memiliki arah, arah dari garis selalu berlawanan dan menuju titik tak terhingga.

\section{Bidang}

Bila garis berdiri sendiri adalah garis, maka bidang adalah himpunan garis yang terdiri lebih dari satu garis, bila garis hanya memiliki ukuran panjang, maka bidang memiliki ukuran selain panjang juga lebar. Bentuk bidang dapat berupa bujur sangkar, persegi panjang, segitiga atau bentuk geometri lainnnya, setiap garis pada bidang tersebut dapat diperbesar ke segala arah.

Asas dwimatra yang akan diterapkan dalam penelitian ini diantaranya adalah:

\section{Keseimbangan}

Gorga : Jurnal Seni Rupa

Volume 10 Nomor 01 Januari-Juni 2021

p-ISSN: 2301-5942 | e-ISSN: 2580-2380

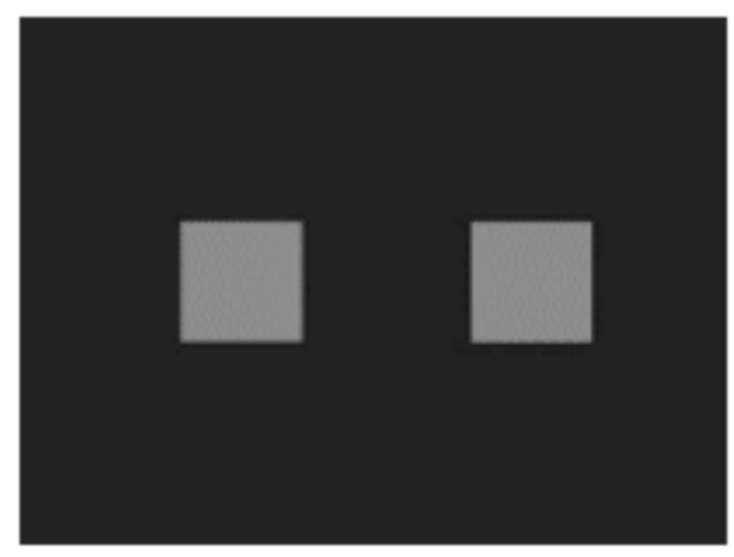

Gambar 2. Keseimbangan. (Thabroni, 2018)

\section{Irama}

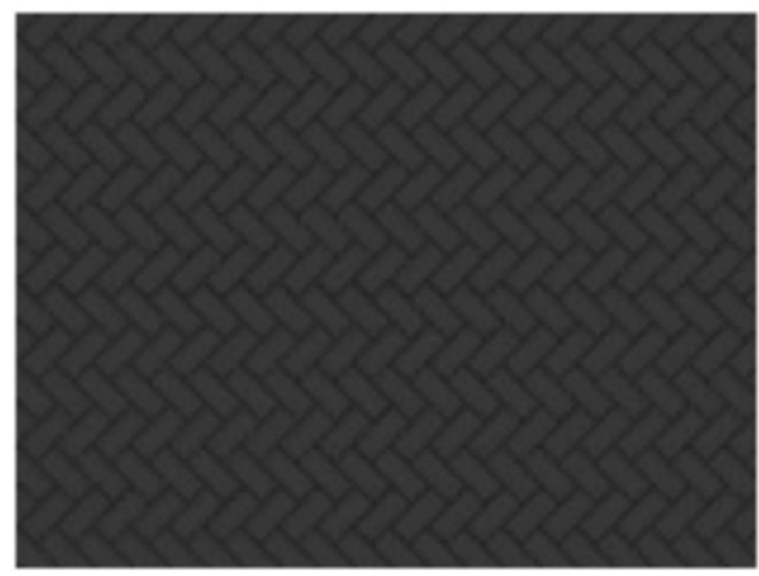

Gambar 3. Irama

(Thabroni, 2018)

\section{Propoorsi}

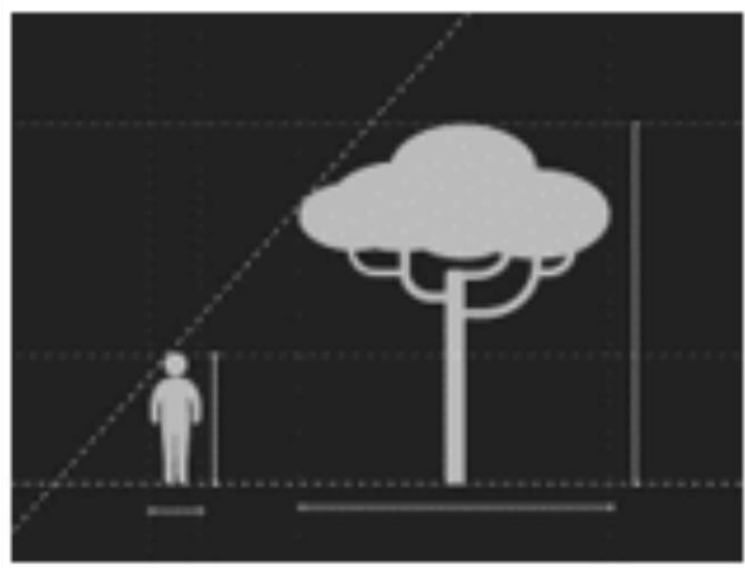

Gambar 4. Proporsi

(Thabroni, 2018)

Penerapan unsur dan asas dwimatra ini memerlukan waktu dikarenakan belum terbiasanya para praktisi mengerjakan hal ini, dengan demikian adalah sebuah kemajuan bila salah satu dari unsur dan asas dwimatra dapat diterapkan dan seterusnya dikembangkan lebih lanjut. 


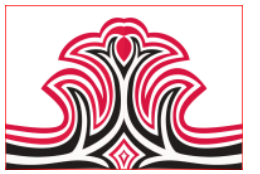

\section{HASIL DAN PEMBAHASAN}

\section{Hasil}

Penerapan konsep dwimatra pada furnitur ini memanfaatkan limbah kayu hasil produksi display toko, potongan-potongan sisa produksi dikumpulkan untuk kemudian disusun sedemikian rupa membentuk produk furnitur. Volume yang dihasilkan dari UKM furnitur tidak terlalu banyak, potongan-potongan sisa masih berukuran cukup besar, jenis sampah lain yang dihasilkan berupa potongan besi, serbuk kayu, sisa lem dan lain sebagainya.

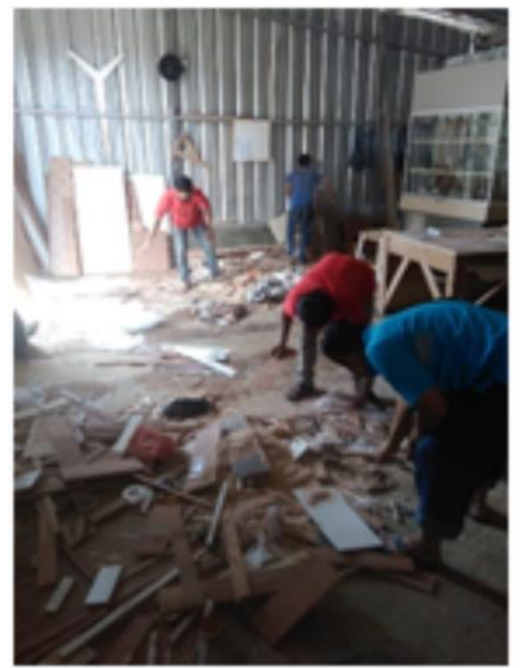

Gambar 5. Suasana Workshop Pasca-Produksi Display. (Muttaqien, 2020)

Pembuatan furnitur dari limbah kayu bekas ini potensinya cukup baik, dengan dimanfaatkannya sisasisa produksi, maka sampah yang dibuang menjadi lebih sedikit, pencemaran lingkungan dapat dikurangi. Secara ekonomi ada peluang, mengingat produkproduk daur ulang kini diminati oleh masyarakat yang sudah paham menjaga lingkungan, namun perlu pendekatan desain yang baik sehingga produk yang dihasilkan layak untuk menjadi komoditas.

Tabel 1. Tabel Contoh Jenis Furnitur.

\begin{tabular}{|l|l|l|}
\hline \multicolumn{1}{|c|}{ Furnitur } & \multicolumn{1}{|c|}{ Jenis } & \multicolumn{1}{|c|}{ Item } \\
\hline Free standing & Kursi/chair & $\begin{array}{l}\text { Side chair, dining chaiv, } \\
\text { arm chair, lounge chair, } \\
\text { etc }\end{array}$ \\
\hline & Meja/table & $\begin{array}{l}\text { Bar table, coffee table, } \\
\text { console table, dining } \\
\text { table, etc }\end{array}$ \\
\hline Built in & Permanen & $\begin{array}{l}\text { Kitchen set, backadrop tv, } \\
\text { walk in closet, etc }\end{array}$ \\
\hline Mobile & Dapat bergerak & $\begin{array}{l}\text { Tempat tidur rumah sakit, } \\
\text { booth berjualan, etc }\end{array}$ \\
\hline Knock down & $\begin{array}{l}\text { Dapat dilepas } \\
\text { pasang }\end{array}$ & $\begin{array}{l}\text { Work station, rak buku, } \\
\text { lemari pakaian }\end{array}$ \\
\hline
\end{tabular}

(Muttaqien, 2020).
Gorga : Jurnal Seni Rupa

Volume 10 Nomor 01 Januari-Juni 2021

p-ISSN: 2301-5942 | e-ISSN: 2580-2380

Jenis furnitur yang dibuat sebagai contoh dipilih jenis Coffee table, jenis meja sederhana dengan ukuran tidak terlalu besar yaitu $60 \mathrm{~cm} \times 40 \mathrm{~cm} \times 35 \mathrm{~cm}(\mathrm{p} \times 1 \times \mathrm{t})$, penerapan unsur garis disini menggunakan potonganpotongan sisa berukuran kecil sampai sedang, pembuatan pola mengambil prinsip irama, proporsi besaran potongan dengan ukuran meja keseluruhan menjadi pertimbangan selanjutnya.
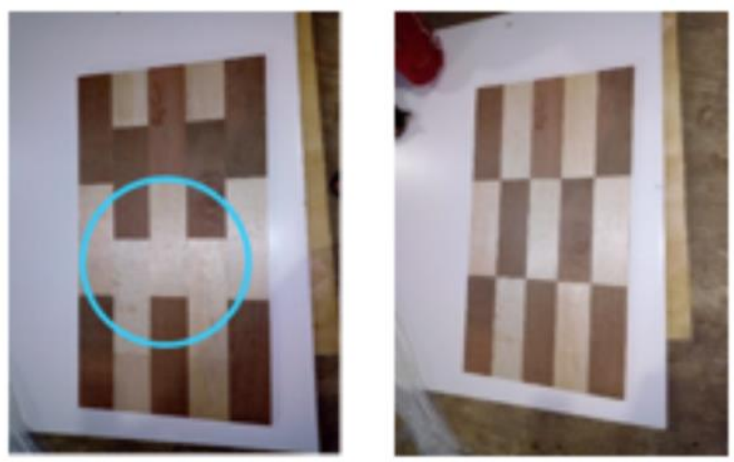

Gambar 6. Proses Pra-Produksi Coffee Table. (Muttaqien, 2020)

\section{Pembahasan}

Pada praktiknya, tidak mudah untuk merubah kebiasaan praktisi kerja kayu yang terbiasa mengolah produk dengan material utuh dan ukuran yang besar, namun dengan pendekatan pembuatan konsep yang tidak terlalu rumit sebagai awal, perlahan dapat menyesuaikan.

Pembuatan pola yang mudah dipahami diambil pola pasang bata yang dimodifikasi sedikit sehingga tidak sama persis. Bentuk bata tampak samping serupa dengan garis atau bidang, komposisi panjang pendek potongan kayu dibuat supaya memiliki unsur keseimbangan, irama dan proporsional secara keseluruhan, sebagai pelengkap, dibuat dua pasang sarana duduk dengan menerapkan pola bendera finish. 

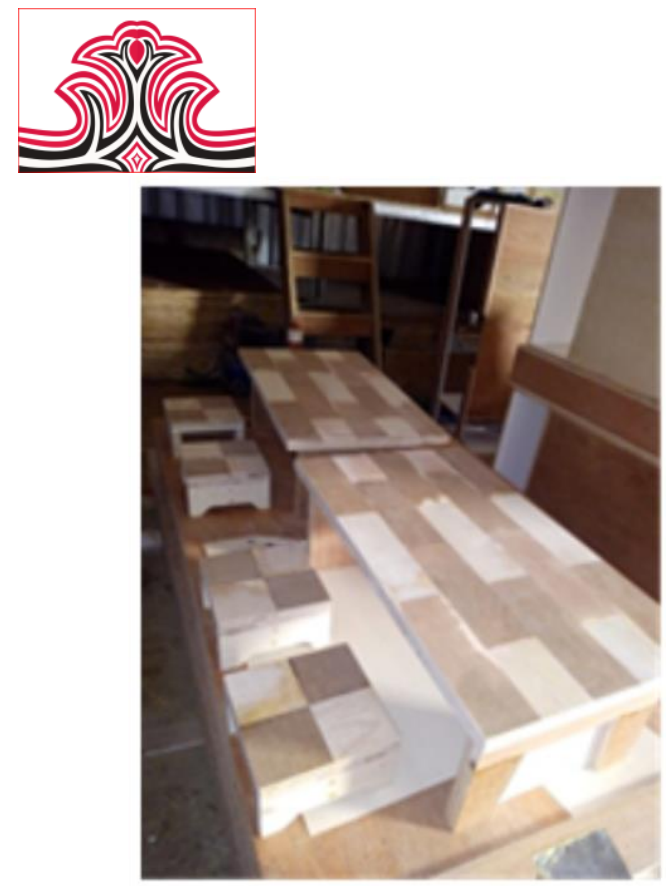

Gambar 7. Coffee Table Bahan Daur Ulang. (Muttaqien, 2020)

\section{KESIMPULAN DAN SARAN}

\section{Kesimpulan}

Pengembangan desain Coffee table dengan menerapkan unsur dwimatra dapat dijadikan alternatif produksi workshop yang terhenti sejenak dimasa pandemi, pembuatan konsep pola dapat dikembangkan lebih lanjut seiring tumbuhnya pemahaman seni rupa pada tim produksi. Penggunaan material limbah sisa pun masih dapat dikembangkan dengan menambahkan material lain yang didapat dari sisa produksi sehingga desainnya dapat lebih di eksplorasi. Penelitian ini menawarkan metode praktik langsung dalam menerapkan pemahaman unsur-unsur seni rupa dengan pendekatan sederhana, prinsip seni rupa dalam hal ini dwimatra yang luwes memungkinkan untuk diserap dengan baik. Keberlanjutan atau sustainable produk daur ulang limbah kayu ini akan terus berlangsung selama kesadaran untuk mengolah limbah dilakukan oleh pelaku UKM.

\section{Saran}

Dalam upaya pengembangan potensi pemanfaatan limbah sisa produksi UKM furnitur, perlu adanya pelatihan yang berkesinambungan untuk tim produksi, produk yang dihasilkan harus dapat dijadikan komoditas yang dapat menghidupi pelaku UKM, strategi pemasaran yang baik dan ekosistem produk daur ulang yang sudah ada harus dimanfaatkan sehingga produk berbasis llimbah ini berkelanjutan dan berkembang.

\section{DAFTAR RUJUKAN}

Dyanrch. (2015). Definisi Dwimatra Dan Trimatra. www.dyanrch.weebly.com (diakses pada 16 Oktober 2020).
Gorga : Jurnal Seni Rupa

Volume 10 Nomor 01 Januari-Juni 2021

p-ISSN: 2301-5942 | e-ISSN: 2580-2380

Hanum, F. (2018). Pemanfaatan Kembali Limbah

Potongan Kayu Menjadi Material Furnitur

Melalui Pendekatan Social Entrepreneurship. Integritas, 90(2), 84-90.

Pambudi, R. (2020). Komunitas Kresek Solo

Jangan Tunggu Terinspirasi, Tapi Bergerak

Untuk Menginspirasi. www.greeners.co (diakses pada 16 Oktober 2020).

Perdana. (2018). Dosen ISI Pamerkan Kreasi Limbah Kayu di Milan. www.radarsolo.jawapos.com (diakses pada 16 Oktober 2020).

Rakhman, F. (2018). Komunitas di Lombok Ini

Perangi Sampah Dengan Daur Ulang. www.mongabay.co.id (diakses pada 16 Oktober 2020).

Rakyat, P. (2016). Produk Limbah Kayu

Indonesia Laris di Pameran Furnitur Eropa.

www.kemenperin.go.id (diakses pada 16 Oktober 2020).

Thabroni, G. (2018). Nirmana Dwimatra Unsur, Asas, Contoh \& Penjelasan Lengkap. www.serupa.id (diakses pada 16 Oktober 2020).

Thabroni, G. (2018). Unsur-Unsur Seni Rupa \& Desain; Diperkuat Pendapat Ahli. www.serupa.id (diakses pada 10 November 2020).

Muttaqien, T.Z. (2020), "Proses Pembuatan Meja Dwimatra”. Hasil Dokumentasi Pribadi: 04 Februari 2020, Universitas Telkom.

Muttaqien, T.Z. (2020), "Proses Pembuatan Meja Dwimatra". Hasil Wawancara Pribadi: 16 Oktober 2020, Universitas Telkom. 